\title{
Application of a mixing-ratios based formulation to model mixing-driven dissolution experiments
}

\author{
Alberto Guadagnini ${ }^{\mathrm{a}, *}$, Xavier Sanchez-Vila ${ }^{\mathrm{b}}$, Maarten W. Saaltink $^{\mathrm{b}}$, Michele Bussini ${ }^{\mathrm{a}}$, Brian Berkowitz ${ }^{\mathrm{c}}$ \\ a Dipartimento di Ingegneria Idraulica, Ambientale, Infrastrutture Viarie, Rilevamento (DIIAR), Politecnico di Milano, Piazza L. Da Vinci, 32,20133 Milano, Italy \\ ${ }^{\mathrm{b}}$ Department of Geotechnical Engineering and Geosciences, Technical University of Catalonia, Gran Capità S/N, 08034 Barcelona, Spain \\ ${ }^{\mathrm{c}}$ Department of Environmental Sciences and Energy Research, Weizmann Institute of Science, Rehovot 76100, Israel
}

\section{A R T I C L E I N F O}

\section{Article history:}

Received 15 February 2008

Received in revised form 13 June 2008

Accepted 2 July 2008

Available online 12 July 2008

\section{Keywords:}

Laboratory experiments

Diffusion and mixing

Multicomponent reactive transport

\begin{abstract}
A B S T R A C T
We address the question of how one can combine theoretical and numerical modeling approaches with limited measurements from laboratory flow cell experiments to realistically quantify salient features of complex mixing-driven multicomponent reactive transport problems in porous media. Flow cells are commonly used to examine processes affecting reactive transport through porous media, under controlled conditions. An advantage of flow cells is their suitability for relatively fast and reliable experiments, although measuring spatial distributions of a state variable within the cell is often difficult. In general, fluid is sampled only at the flow cell outlet, and concentration measurements are usually interpreted in terms of integrated reaction rates. In reactive transport problems, however, the spatial distribution of the reaction rates within the cell might be more important than the bulk integrated value. Recent advances in theoretical and numerical modeling of complex reactive transport problems [De Simoni M, Carrera J, Sanchez-Vila X, Guadagnini A. A procedure for the solution of multicomponent reactive transport problems. Water Resour Res 2005;41:W11410. doi: 10.1029/2005WR004056, De Simoni M, Sanchez-Vila X, Carrera J, Saaltink MW. A mixing ratios-based formulation for multicomponent reactive transport. Water Resour Res 2007;43:W07419. doi: 10.1029/2006WR005256] result in a methodology conducive to a simple exact expression for the space-time distribution of reaction rates in the presence of homogeneous or heterogeneous reactions in chemical equilibrium. The key points of the methodology are that a general reactive transport problem, involving a relatively high number of chemical species, can be formulated in terms of a set of decoupled partial differential equations, and the amount of reactants evolving into products depends on the rate at which solutions mix. The main objective of the current study is to show how this methodology can be used in conjunction with laboratory experiments to properly describe the key processes that occur in a complex, geochemically-active system under chemical equilibrium conditions. We model three $\mathrm{CaCO}_{3}$ dissolution experiments reported in Singurindy et al. [Singurindy O, Berkowitz B, Lowell RP. Carbonate dissolution and precipitation in coastal environments: Laboratory analysis and theoretical consideration. Water Resour Res 2004;40:W04401. doi: 10.1029/2003WR002651, Singurindy O, Berkowitz B, Lowell RP. Correction to Carbonate dissolution and precipitation in coastal environments: laboratory analysis and theoretical consideration. Water Resour Res 2005;41:W11701. doi: 10.1029/2005WR004433], in which saltwater and freshwater were mixed in different proportions. The integrated reaction rate within the cell estimated from the experiments are modeled independently by means of (a) a state-of-the-art reactive transport code, and (b) the uncoupled methodology of $[12,13]$, both of which use dispersivity as a single, adjustable parameter. The good agreement between the results from both methodologies demonstrates the feasibility of using simple solutions to design and analyze laboratory experiments involving complex geochemical problems.
\end{abstract}

(c) 2008 Elsevier Ltd. All rights reserved.

\section{Introduction}

Mixing of waters with different chemical composition is the direct outcome of various processes, including diffusion and disper-

\footnotetext{
* Corresponding author. Fax: +39 223996298.

E-mail address: alberto.guadagnini@polimi.it (A. Guadagnini).
}

sion. Mixing governs key issues associated with the evolution of surface and subsurface water bodies, including hydrochemistry patterns of aquatic systems [1,55], the geochemistry of carbonate systems (e.g., $[10,34,36,44,48])$ and microbial reactions involved in risk and vulnerability studies associated with groundwater reservoirs $[5,6,24,30]$. As such, significant efforts have been devoted to the characterization of mixing and its effects on the environment $[19,23]$. 
The complete analysis of a reactive transport problem usually involves specification of a large number of aqueous and non-aqueous species. An efficient approach to analyzing multicomponent reactive transport relies on the concept of mapping mixing proportions, or mixing ratios, to reactive-species concentrations (e.g., $[1,52]$, and references therein). Mixing ratios can be obtained at a given location upon measuring a number of conservative species and applying mass balance considerations. Recent methodologies incorporate the possibility of accounting for uncertainty in the chemical composition of end-members and sampling uncertainties $[4,39]$.

De Simoni et al. [13] present a mixing ratios-based formulation to solve reactive transport problems in the case of equilibrium aqueous reactions and precipitation/dissolution of minerals induced by mixing of different solutions. Within this context, one starts by defining end-member waters, i.e., waters that have characteristic chemical signatures. A vector of mixing ratios (or proportions) $\boldsymbol{\beta}=\left(\beta_{1}, \ldots, \beta_{N}\right)$ is then introduced, with $\beta_{i}$ representing the proportion of end-member $i(i=1, \ldots, N)$ in a water sample. In a system with $N$ end-members, this results in $(N-1)$ independent variables, because the restriction $\sum_{i=1}^{N} \beta_{i}=1$ applies. From consideration of the distribution of mixing ratios, together with a speciation process, it is then possible to evaluate directly the spatial and temporal distribution of reaction rates. These, in turn, control the local amount of reactants evolving into products; they are key quantities to assess the distribution of chemical compounds of interest in a system.

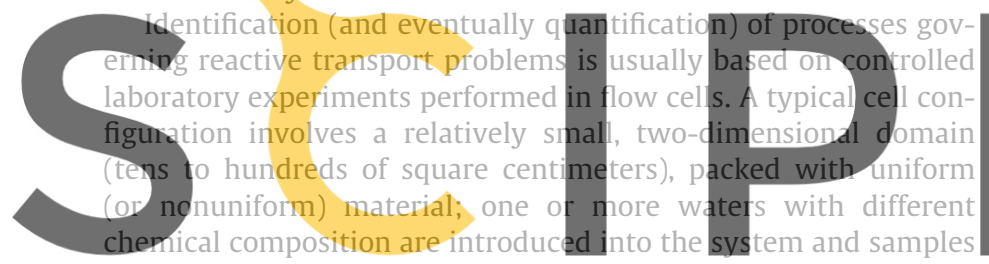
are taken either at internal points and/or at the outflow boundaries. The advantages of such experiments with respect to the anal-

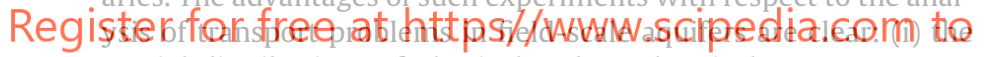
spatial distributions of physical and geochemical parameters can be known by construction; (ii) boundary and initial conditions are relatively easily established; (iii) experiments are fast and well-controlled; and (iv) measuring devices are simpler and easier to handle than those used in the field.

A drawback of flow cells, on the other hand, is the difficulty usually associated with extensively measuring the spatial distribution of any state variable of interest within the cell itself. Extrapolation of the behavior observed in flow cells to field-scale systems is another major concern. The former problem can be addressed by incorporation of multiple ports in the cell design, to allow local measurements at selected points; however, this is only a partial solution, as only very limited amounts of liquid can be withdrawn without disturbing the flow field and the reaction dynamics. An additional problem of such a setup is that while ports could allow measurement of the desired concentrations of several species, there is no direct possibility of measuring the space-time evolution of the reaction rates taking place within the cell. Reactions can be measured in only a few cases, e.g., where the products of the reactions lead to changes in color or luminescence and can be measured indirectly (e.g., $[7,19])$.

In practice, therefore, reaction rates in flow cell experiments are obtained indirectly by means of mass balance arguments. The temporal evolution of the inlet and outlet concentrations of reactants provides an integrated measure of the total reaction taking place within the cell, but obviously does not provide the detailed space-time pattern of local rates within the cell. Thus, importantly, this information is insufficient to identify the position and magnitude of the maximum local rate, which has a significant impact on porosity changes and potential development of change in rock hydraulic properties (e.g., formation of wormholes in dissolution problems, or occurrence of clogging phenomena in precipitation or biological problems) (e.g., [11,14,16,25,31,47], and references therein). In general, this information can be obtained only at the end of an experiment, upon dismantling the cell and measuring the time-integrated local change in porosity (or mineral concentration). Even in this case, the detailed time evolution of local reaction rates cannot be captured.

A common method to obtain estimates of spatial distributions of chemical species concentrations and reaction rates is to employ numerical modeling, which can be based on a variety of mathematical formulations (e.g., $[9,18,26,28,32,35,37,38,40,41,50,51,53])$. The resulting sets of governing equations have been included in a large number of reactive transport codes that can treat transport of multiple species with different types of reactions (see [42] for a list of codes). They typically formulate the reactive transport problem by using components (sometimes referred to as master species), that can be defined as linear combinations of the concentrations of chemical species. In some cases the transport equations of these components become conservative (i.e., independent of reactions) and decoupled from each other. This happens when (a) the concentrations of the reacting species stand in algebraic relationship to each other, and (b) the coefficients describing physical mixing do not differ between species. The former requirement is met by systems either in local chemical equilibrium or instantaneous, complete, irreversible reactions (e.g., $[21,27]$ ) and can also be used for specific

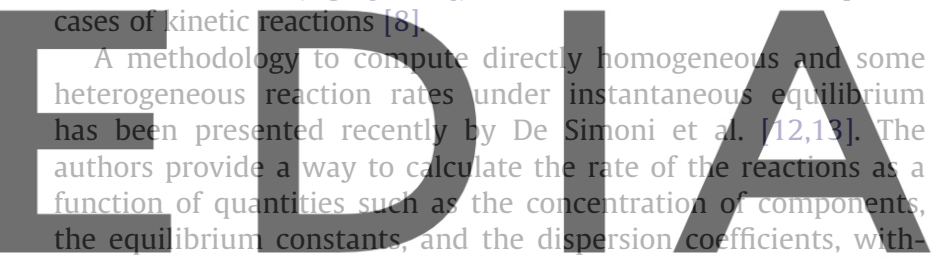
out the need to actually evaluate the concentration of the dissolved species. Their results show that the problem of assessing

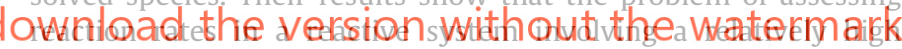
number of aqueous and constant activity species can be decoupled into a transport problem posed in terms of mixing ratios plus a speciation term. The general expression for the reaction rates illustrates that mixing processes control equilibrium reaction rates. As compared to formulations proposed previously in the literature (e.g., $[18,28,37,38,40,41,50])$, this method is simpler and more concise and conducive to an analytical expression for the reaction rates that includes the model of Phillips' [33] as a particular case. It allows direct evaluation of the distribution of reaction rates of a complex multispecies reactive transport problem, which is usually solved only numerically, by means of solving two independent problems: (a) the transport of one or more conservative species, and (b) chemical speciation. The solution to each of these problems is simpler than the solution of the complete problem and in some cases it is possible to obtain closedform analytical solutions.

The main aim of this paper is to show how this methodology can be used in conjunction with laboratory experiments to properly describe the key processes that occur in a complex, geochemically active system under chemical equilibrium conditions. To achieve this goal we compare the analyses of some of the laboratory experiments reported by Singurindy et al. $[48,49]$ on the basis of (a) a state-of-the-art numerical code that allows solution of the reactive transport problem in an accurate and efficient way, and (b) the uncoupled approach of De Simoni et al. [12,13], and assess the use of the latter as a valid alternative to studying the pattern of precipitation/dissolution within the experimental flow cell. The experiments analyzed here focus on calcium carbonate dissolution within saltwater-freshwater mixing zones. 


\section{Overview of the experiments}

The experimental setup described in $[48,49]$ consisted of a $16 \times 16 \times 1 \mathrm{~cm}^{3}$ flow cell packed with $\mathrm{CaCO}_{3}$ particles, to produce a uniform, porous system. The cell was connected to two inlet reservoirs: one containing $40 \mathrm{~g} / \mathrm{L} \mathrm{NaCl}$ dissolved in double deionized water (hereafter called "saltwater") and the other containing only double deionized water ("freshwater"). Before injection into the cell, both waters were brought into contact with calcite and with $\mathrm{CO}_{2}$ at a partial pressure of $1 \mathrm{~atm}$ until conditions of chemical equilibrium were obtained. Further details regarding the setup are reported in [48].

Here, we focus mainly on the three dissolution experiments reported in that work. The experiments differ from each other in terms of the ratio between fresh and saltwater flow inlet rates, as described in Table 1 . The total volumetric flow rate, $Q$, comprising both freshwater and saltwater, is the same in all three experiments $\left(Q=1.44 \times 10^{-3} \mathrm{~m}^{3}\right.$ day $\left.^{-1}\right)$. On the basis of measurements of cumulative differences between inlet and outlet $\mathrm{Ca}^{2+}$ concentrations, Singurindy et al. $[48,49]$ calculated a global dissolution rate for the system. Key experimental results are reported in Table 2.

Singurindy et al. $[48,49]$ then compared the measured dissolution rates against those estimated using the theory of Phillips [33], which describes mineral precipitation/dissolution. A simplified geometry was adopted to characterize the extent of the region within which mixing actually occurs in the system and a constant (small-scale) dispersivity value was used for all three dissolution
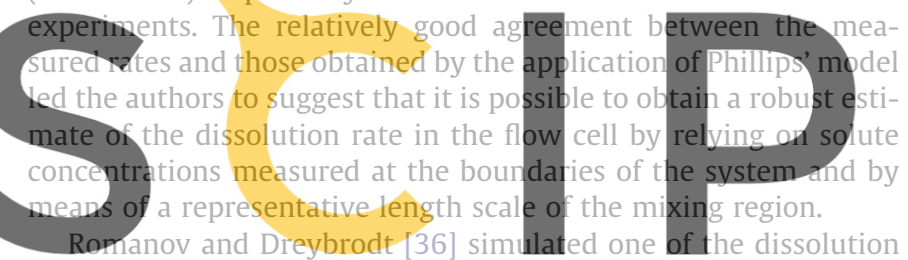
experiments of Singurindy et al. [48] by an uncoupled methodology based on the theory of Phillips [33]. Upon solving numerically

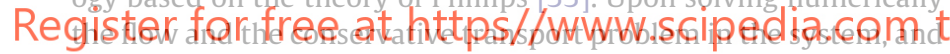
simply prescribing an isotropic dispersivity value of the order of the mean size of the rock grains in the flow cell, Romanov and Dreybrodt [36] concluded that the methodology is capable of providing estimates of the porosity evolution measured from the experiment, without the need to calibrate dispersivity. Romanov and Dreybrodt [36] obtained a value of porosity change only half of that obtained in $[48,49]$, but they considered the comparison satisfactory, suggesting that the experimental uncertainty associated with the measurements is approximately $50 \%$.

Table 1

Flow rates and flow ratios in the dissolution experiments of Singurindy et al. $[48,49]$

\begin{tabular}{llll}
\hline Experiment & $\begin{array}{l}\text { Ratio fresh/ } \\
\text { saltwater }(\% / \%)\end{array}$ & $\begin{array}{l}\text { Flow rate of freshwater, } \\
Q_{\text {in,f }}\left(\mathrm{m}^{3} \mathrm{day}^{-1}\right)\end{array}$ & $\begin{array}{l}\text { Flow rate of saltwater, } \\
\mathrm{Qin}, \mathrm{s}_{\left(\mathrm{m}^{3} \mathrm{day}^{-1}\right)}\end{array}$ \\
\hline 1 & $50 / 50$ & $7.2 \times 10^{-4}$ & $7.2 \times 10^{-4}$ \\
2 & $30 / 70$ & $4.3 \times 10^{-4}$ & $10.1 \times 10^{-4}$ \\
3 & $70 / 30$ & $10.1 \times 10^{-4}$ & $4.3 \times 10^{-4}$ \\
\hline
\end{tabular}

\section{Methodology for experiments interpretation}

\subsection{Mathematical description of the experiment}

To fully model the reported dissolution experiments it is necessary to know in detail the chemical composition of the fresh and salt water at the inlet reservoirs, the parameters controlling flow and transport (hydraulic conductivity, porosity, diffusion/dispersion coefficients), and the equilibrium constants for the controlling reactions.

We start by using the code PHREEQC [32] to calculate the chemical composition of the two inflowing waters used in the experiments under the assumption of equilibrium with respect to calcite and a partial $\mathrm{CO}_{2(\mathrm{~g})}$ pressure of $1 \mathrm{~atm}$ (see Table 3). PHREEQC also provides the relevant aqueous complexation reactions. The complete chemical system is formed by 19 chemical species and 13 reactions. All reactions and their equilibrium constants are displayed in Table 1 .

We describe transport as governed locally by a two-dimensional advection-dispersion equation (ADE) with a sink/source term to account for dissolution. We discuss the implications of adopting the ADE in Section 5. Species mass balance can then be written as

Table 3

Chemical characteristics of the two inflow waters

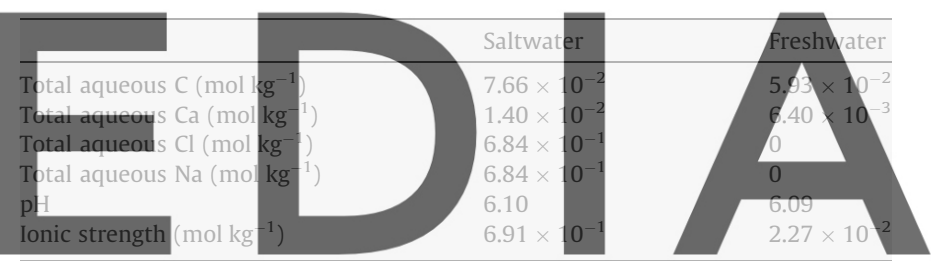

Both are in equilibrium with respect to calcite and have partial $\mathrm{CO}_{2(\mathrm{~g})}$ pressure of 1 atm.

\section{download the version without the watermark}

Table 4

Chemical reactions with their $\log$ equilibrium constants, $\log K$, used in the reactive transport simulations

\begin{tabular}{lr}
\hline Reaction & \multicolumn{1}{c}{$\log K$} \\
\hline $\mathrm{CaCl}^{+}=\mathrm{Ca}^{2+}+\mathrm{Cl}^{-}$ & 0.6938 \\
$\mathrm{CaCl}_{2(\mathrm{aq})}=\mathrm{Ca}^{2+}+2 \mathrm{Cl}^{-}$ & 0.6283 \\
$\mathrm{CaHCO}_{3}^{+}=\mathrm{Ca}^{2+}+\mathrm{HCO}_{3}^{-}$ & 1.0606 \\
$\mathrm{CaOH}^{+}+\mathrm{H}^{+}=\mathrm{Ca}^{2+}+\mathrm{H}_{2} \mathrm{O}$ & 12.9321 \\
$\mathrm{CO}_{2}(\mathrm{aq})+\mathrm{H}_{2} \mathrm{O}=\mathrm{HCO}_{3}^{-}+\mathrm{H}^{+}$ & -6.3636 \\
$\mathrm{CO}_{3}^{2-}+\mathrm{H}^{+}=\mathrm{HCO}_{3}^{-}$ & 10.3524 \\
$\mathrm{OH}^{-}+\mathrm{H}^{+}=\mathrm{H}_{2} \mathrm{O}$ & 14.0707 \\
$\mathrm{HCl}_{(\mathrm{aq})}=\mathrm{H}^{+}+\mathrm{Cl}^{-}$ & 0.6693 \\
$\mathrm{NaCl}_{(\mathrm{aq})}=\mathrm{Na}^{+}+\mathrm{Cl}^{-}$ & 0.7811 \\
$\mathrm{NaCO}_{3}^{-}+\mathrm{H}^{+}=\mathrm{Na}^{+}+\mathrm{HCO}_{3}^{-}$ & 9.8145 \\
$\mathrm{NaHCO}_{3(\mathrm{aq})}=\mathrm{Na}^{+}+\mathrm{HCO}_{3}^{-}$ & -0.1715 \\
$\mathrm{NaOH}_{(\mathrm{aq})}+\mathrm{H}^{+}=\mathrm{Na}^{+}+\mathrm{H}_{2} \mathrm{O}$ & 14.2479 \\
$\mathrm{CaCO}_{3(\mathrm{~s})}+\mathrm{H}^{+}=\mathrm{Ca}^{2+}+\mathrm{HCO}_{3}^{-}$ & 1.8789 \\
\hline $\mathrm{A}^{-}$ &
\end{tabular}

A uniform temperature, $T=23^{\circ} \mathrm{C}$, is assumed (see $[48,49]$ ).

Table 2

Experimental reaction rates for dissolution reported by Singurindy et al. $[48,49]$

\begin{tabular}{|c|c|c|c|}
\hline Experiment & $\begin{array}{l}\text { Ratio fresh/saltwater } \\
(\% / \%)\end{array}$ & $\begin{array}{l}\left.\text { Experimental rate (relative to the mixing volume, } V_{\mathrm{e}}\right) \\
\left(\mathrm{kg} \mathrm{m}^{-3} \mathrm{day}^{-1}\right)\end{array}$ & $\begin{array}{l}\left.\text { Experimental rate (relative to the total cell volume, } V_{\text {cell }}\right) \\
\left(\mathrm{kg} \mathrm{m}^{-3} \mathrm{day}^{-1}\right)\end{array}$ \\
\hline 1 & $50 / 50$ & 0.180 & 0.157 \\
\hline 2 & $30 / 70$ & 0.130 & 0.057 \\
\hline 3 & $70 / 30$ & 0.730 & 0.277 \\
\hline
\end{tabular}

Here, $V_{\mathrm{e}}$ is the mixing volume as defined by Singurindy et al. [48] and $V_{\text {cell }}$ is the total volume of the flow cell. 
$\frac{\partial(\mathbf{m})}{\partial t}=\mathbf{M} L(\mathbf{c})+\mathbf{f}$.

Here, vector $\mathbf{m}$ contains the mass of species per unit volume of medium and vector $\mathbf{c}$ contains species concentrations $(\mathbf{m}=\phi \mathbf{c}$ for mobile species in a medium of porosity $\phi$ ). Matrix $\mathbf{M}$ is diagonal and its diagonal terms are unity when a species is mobile and zero otherwise; $\mathbf{f}$ is a source/sink term which is used to represent chemical reactions. The linear operator $L(c)$ in (1) is defined as $L(c)=-\nabla \cdot(\phi \mathbf{v} c)+\nabla \cdot(\phi \mathbf{D} \nabla c)$, where $\mathbf{D}$ is the dispersion tensor and $\mathbf{v}$ is the fluid velocity. Here, we assume that $\mathbf{D}$ and the advective velocity field are the same for all species. Under instantaneous equilibrium conditions, $\mathbf{f}=\mathbf{S}_{\mathrm{e}}^{\mathrm{T}} \mathbf{r}$, where $\mathbf{r}$ is the vector of reaction rates (expressed per unit volume of medium) and $\mathbf{S}_{\mathrm{e}}$ is the stoichiometric matrix of the chemical system $\left(\mathbf{S}_{\mathrm{e}}\right.$ is here an $N_{\mathrm{r}} \times N_{\mathrm{s}}$ matrix, $N_{\mathrm{r}}=13$ and $N_{\mathrm{s}}=19$ being the number of reactions and of chemical species, respectively).

Equilibrium is described by the mass action law, which can be written as $\boldsymbol{S}_{\mathrm{e}} \log \mathbf{a}=\log \mathbf{K}$, where $\mathbf{K}$ is the vector of chemical equilibrium constants and a is the vector of species activities. Some species (here called constant activity species), such as water and minerals, can be assumed to have unit activity. In general, the activity of aqueous species, $\mathbf{a}_{\mathrm{a}}$, is a nonlinear function of aqueous species concentration, $\mathbf{c}_{\mathrm{a}}$, which can be written as

$\log a_{\mathrm{a}}=\log c_{\mathrm{a}}+\log \gamma\left(c_{\mathrm{a}}\right)$

Activity coefficients, $\gamma$, of the aqueous species are calculated in terms of the ionic strength, I, through the extended Debye-Hückel

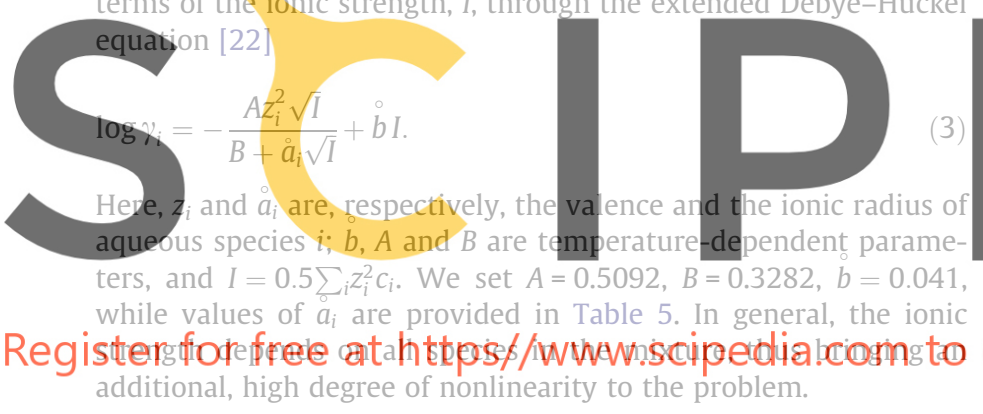

\subsection{Numerical geochemical modeling approach}

The flow and reactive transport problem is modeled with the numerical code RETRASO [42]. In this case, according to [40,42] reactive transport solved upon splitting the vector of 19 concentrations in (1) into two parts, $\mathbf{c}_{\mathrm{a}}$ and $\mathbf{c}_{\mathrm{c}}$, respectively containing constant activity and aqueous species concentrations. The mineral, $\mathrm{CaCO}_{3}$ and water are considered as constant activity species in this application. Amongst the elements of vector $\mathbf{c}_{\mathrm{a}}$ one can then define 4 primary species and 13 secondary species. This results into four conservative components. Each one of these is a linear combination of concentrations of the four selected primary species and obeys a conservative format of the ADE with appropriate boundary and initial conditions. Thus, the complete numerical solution of the reactive transport problem entails: (a) solving four conservative ADEs, (b) performing speciation calculations, consisting in the solution of a nonlinear system of 17 algebraic equations, and finally (c) calculating numerically the reaction rates by solving the 13 transport equations with the format of (1) satisfied by the secondary species.

Fig. 1 shows the domain employed in the numerical simulations of the flow and transport. We examine mixing under steady-state flow within a homogeneous, two-dimensional porous domain. A uniform intrinsic permeability of $k=3.975 \times 10^{-10} \mathrm{~m}^{2}$ [46] was adopted. Inflow boundaries are modeled by imposing a constant volumetric flux, uniformly distributed along the inlet boundaries according to the flow rates distributions presented in Table 1. A constant head equivalent to atmospheric pressure is imposed at the outflow boundaries. Porosity, $\phi$, was set to the measured value of 0.33 [48].

Transport parameters, i.e., dispersivities, are calibrated for the experiments by comparing the calculated total rates to experimental rates (reported in Table 2). The latter are derived on the basis of the available experimental data (Fig. 4 in $[48,49]$ ), which consist of the overall dissolved calcite concentrations, $c_{\mathrm{CaCO}_{3}}^{t}$, evaluated at times $t$, and computed by mass balance from the inflow and outflow $\mathrm{Ca}^{2+}$ concentrations by means of

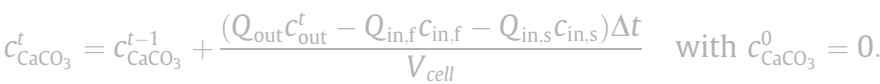

Here, $V_{\text {cell }}$ is the volume of the flow cell; $Q_{\text {out }}, Q_{\text {in,f }}$ and $Q_{\text {in,s }}$, respectively, are the flow rates at the outflow, freshwater inflow and saltwater inflow boundaries; $c_{\mathrm{in}, \mathrm{f}}$ and $c_{\mathrm{in}, \mathrm{s}}$ are the total aqueous $\mathrm{Ca}^{2+}$ concentration $\left(c_{\mathrm{Ca}}\right)$ in the inflow freshwater and saltwater, as pro-

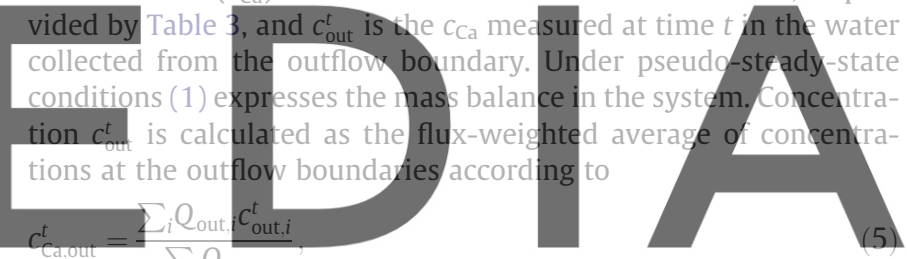
$\sum_{i} Q_{\text {out }, i}$

where $i$ indicates nodes at the outflow boundary. Because exper

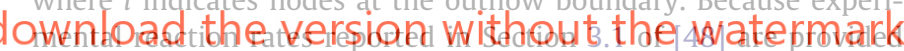
in terms of an effective volume of the mixing zone, we rescaled them to express dissolution rates in terms of the total cell volume, to avoid ambiguities in the comparison (see Table 2).

The domain was discretized into square finite elements (Fig. 1). From preliminary analysis of the impact of grid size, $\Delta$, upon the total computed reaction rates, we adopted a value of $\Delta=0.133 \mathrm{~cm}$, i.e., $120 \times 120$ elements. This restricts the longitudinal dispersivity values $\alpha_{\mathrm{L}}$ that can be used in the numerical analysis according to the numerical Peclet condition $\left(\Delta<2 \alpha_{\mathrm{L}}\right)$, to avoid numerical instabilities. We note that dissolution may lead to changes in medium properties, specifically in porosity and groundwater velocity. To assess the importance of these effects, we simulate the experiments both by including and excluding porosity variability in the numerical simulations. When variability of porosity is considered, permeability updating is performed on the basis of Kozeny's relationship (e.g., [2]). Updating porosity and permeability values at each time step led to no significant difference in the calculated global dissolution rates. This is explained by noting that the experiments were performed within the time frame of a few hours, so that modifications in the amount of calcite affected

Table 5

Ionic radius, $\stackrel{\circ}{a}$, of the system species

\begin{tabular}{|c|c|c|c|c|c|c|c|c|c|}
\hline Species & $\mathrm{H+}$ & $\mathrm{Na}+$ & $\mathrm{Ca}^{2+}$ & $\mathrm{HCO}_{3}^{-}$ & $\mathrm{Cl}^{-}$ & $\mathrm{CaCl}^{+}$ & $\mathrm{CaCl}_{2(\mathrm{aq})}$ & $\mathrm{CaHCO}_{3}^{+}$ & $\mathrm{CaOH}^{+}$ \\
\hline${\stackrel{\bar{a}}{a_{i}}}$ & 9.0 & 4.0 & 6.0 & 4.0 & 3.0 & 4.0 & $-{ }^{a}$ & 4.0 & 4.0 \\
\hline Species & $\mathrm{CO}_{2(\mathrm{aq})}$ & $\mathrm{CO}_{3}^{2-}$ & $\mathrm{OH}^{-}$ & $\mathrm{HCl}_{(\mathrm{aq})}$ & $\mathrm{NaCl}_{(\mathrm{aq})}$ & $\mathrm{NaCO}_{3}^{-}$ & $\mathrm{NaHCO}_{3(\mathrm{aq})}$ & $\mathrm{NaOH}_{(\mathrm{aq})}$ & \\
\hline${\stackrel{\bar{a}}{a_{i}}}$ & $-^{a}$ & 5.0 & 3.0 & $-^{a}$ & $-^{\mathrm{a}}$ & 4.0 & $-^{a}$ & $-^{a}$ & \\
\hline
\end{tabular}

a The charge $\left(z_{i}\right)$ of $\mathrm{CaCl}_{2(\mathrm{aq})}, \mathrm{CO}_{2(\mathrm{aq})}, \mathrm{HCl}_{(\mathrm{aq})}, \mathrm{NaCl}_{(\mathrm{aq})}, \mathrm{NaHCO}_{3(\mathrm{aq})}$, and $\mathrm{NaOH}_{(\mathrm{aq})}$ is zero; therefore, according to (3), $\stackrel{\circ}{a}_{i}$ is irrelevant. 
Fresh water inlet - Constant flow rate
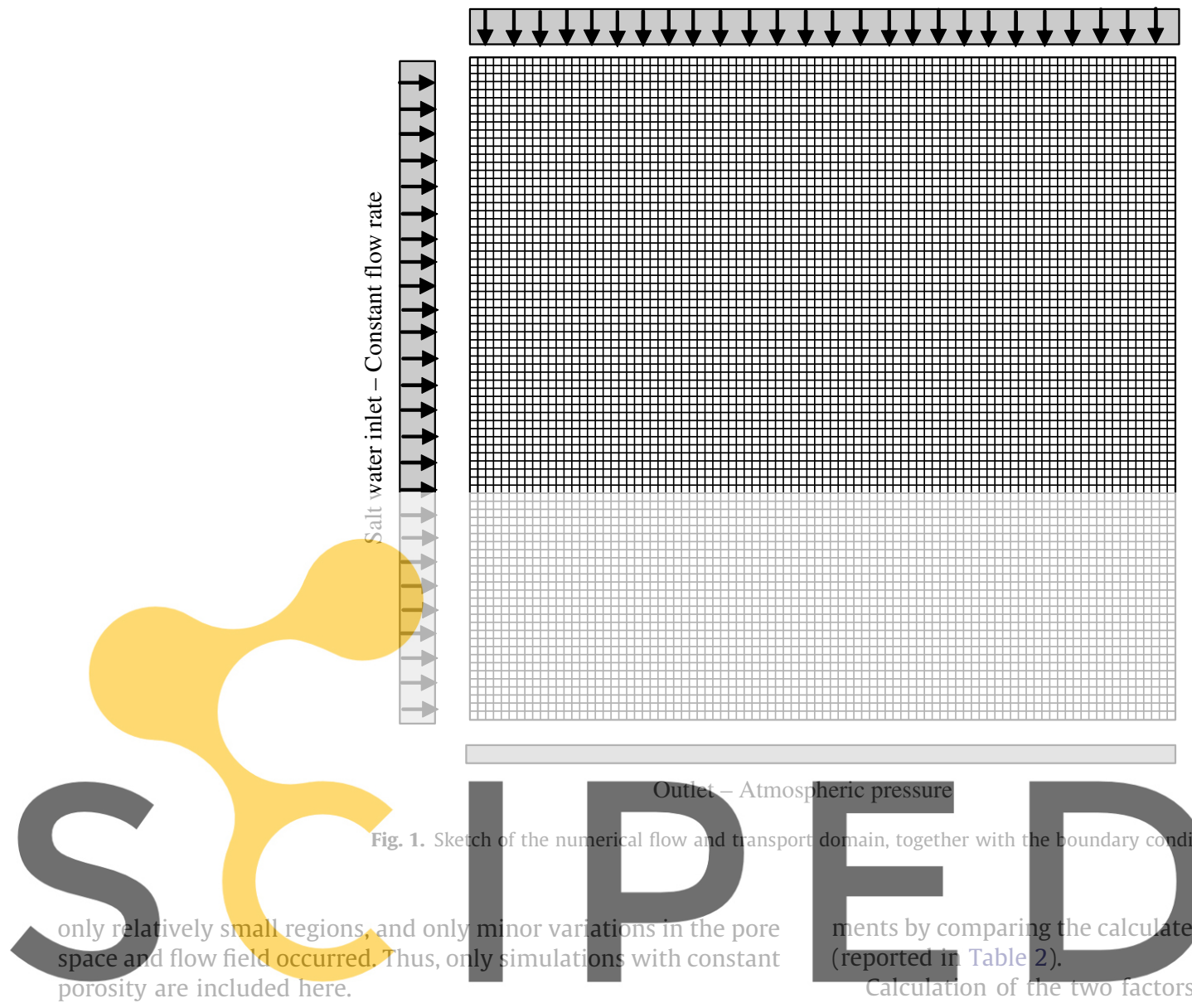

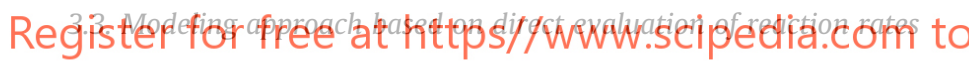

In the case of two end-members, the chemical problem is characterized completely by a single mixing ratio, $\beta$. Assuming that solute transport can be properly described by means of an advection-dispersion (or advection-diffusion) equation (see Section 5 for comments regarding this particular choice), De Simoni et al. [13] provided an explicit expression for the computation of reaction rates $r$ in terms of $\beta$

$r=\phi \underbrace{\frac{\partial^{2} c_{\mathrm{Ca}}}{\partial \beta^{2}}}_{A} \underbrace{\nabla \beta^{\mathrm{T}} \mathbf{D} \nabla \beta}_{B}$,

where $r$ is expressed in $\mathrm{mol} \mathrm{kg}^{-1} \mathrm{~s}^{-1}$. Eq. (6) indicates that reaction rates depend on chemistry, which controls the nonlinear term, $A \equiv \partial^{2} c_{\mathrm{Ca}} / \partial \beta^{2}$, and on transport processes, through the gradient of the values of $\beta$ and the dispersion tensor, $\mathbf{D}$. In our geochemical setup $c_{\mathrm{Ca}}$ in (6) corresponds to total calcium (i.e., Ca present in any of the aqueous species enumerated in Table 4), because $1 \mathrm{~mol}$ of dissolved calcite leads to an increase in $1 \mathrm{~mol}$ in the total aqueous calcium species. The hypotheses underlying (6) are that (i) the mobile species are subject to the same advective flow field, and (ii) the same dispersion processes apply to all species, with equal dispersion coefficients. The formulation does not impose any additional restrictions on the nature of flow, i.e., flow can be steady or transient, and fully or partially saturated. We calculate the local distribution of rates under pseudo-steady-state transport conditions at constant temperature according to (6), and then integrate it over the flow cell volume to obtain the total reaction rate within the system. Dispersivities are then calibrated for each of the three experi-

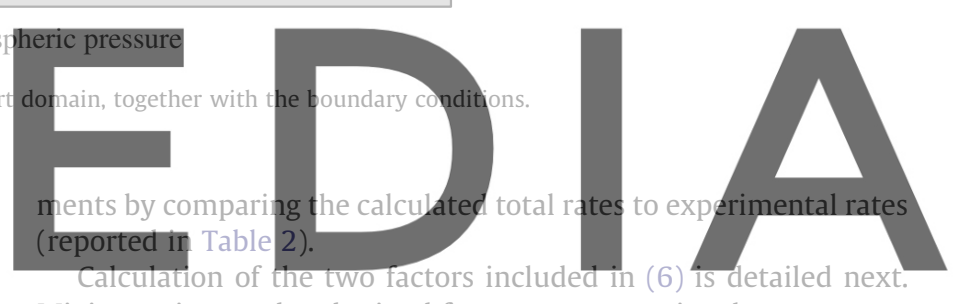

Mixing ratios can be obtained from any conventional transport or tracer transport, and therefore, the partial distribution of $\beta$ at pseudo-steady-state conditions, with the widely tested random walk particle tracking code RW3D [17,43]. The approach is computationally efficient and is not affected by problems associated with numerical dispersion. The random walk code is completely integrated with the flow simulator. The code uses a hybrid scheme for the velocity interpolation that provides local as well as global divergence-free velocity fields within the solution domain, and a continuous dispersion tensor field that approximates well mass balance at grid interfaces of adjacent cells [43]. A constant-displacement scheme [54] that automatically modifies the time step size for each particle according to the local velocity is employed, to decrease computational effort.

The nonlinear chemistry-related factor, $A$, in (6) can be calculated by plotting the total aqueous calcium concentration, $c_{\mathrm{Ca}}$, versus mixing ratio $\beta$ for a suite of arbitrary mixing scenarios. This step in the analysis can be accomplished without the need to solve the fully coupled reactive transport problem, because

Table 6

Sensitivity of the global dissolution rate in the system calculated by RETRASO for experiment 1 of Table 1 to different values adopted for $\alpha_{\mathrm{L}}$ and $\alpha_{\mathrm{T}}$

\begin{tabular}{lll}
\hline$\alpha_{\mathrm{T}}(\mathrm{mm})$ & $\alpha_{\mathrm{L}}(\mathrm{mm})$ & Simulated global dissolution rate $\left(\mathrm{kg} \mathrm{m}^{-3}\right.$ day $\left.^{-1}\right)$ \\
\hline 5.0 & 1.0 & 0.353 \\
1.0 & 5.0 & 0.156 \\
5.0 & 5.0 & 0.351 \\
0.7 & 0.7 & 0.123 \\
1.0 & 0.7 & 0.155 \\
1.0 & 1.0 & 0.156 \\
\hline
\end{tabular}



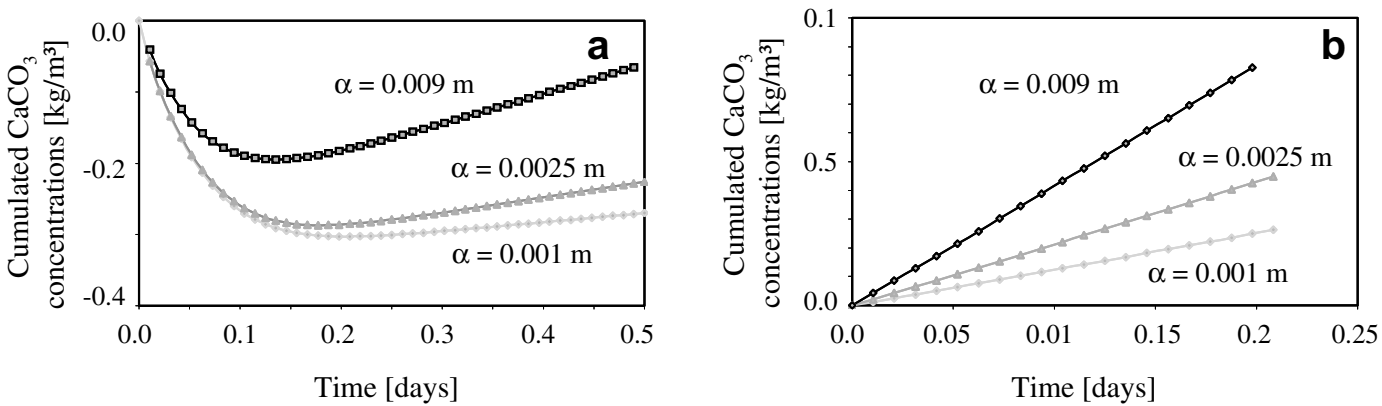

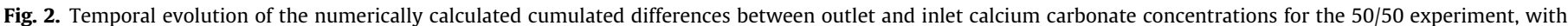

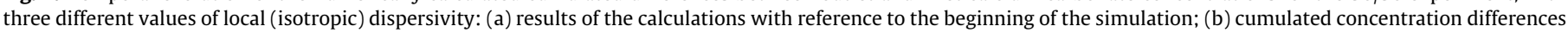

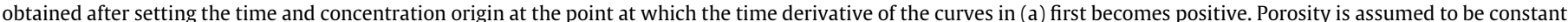
for the duration of the experiments.

the dependence of $c_{\mathrm{Ca}}$ on $\beta$ can be calculated by existing speciation codes, such as PHREEQC. Instead, for reasons of consistency we used an internal package in RETRASO. Then $\partial^{2} \mathrm{C}_{\mathrm{Ca}} / \partial \beta^{2}$ can be calcu-

Table 7

Results of the numerical simulations for the three scenarios investigated, in terms of dispersivity providing the best match between measured and modeled dissolution rates

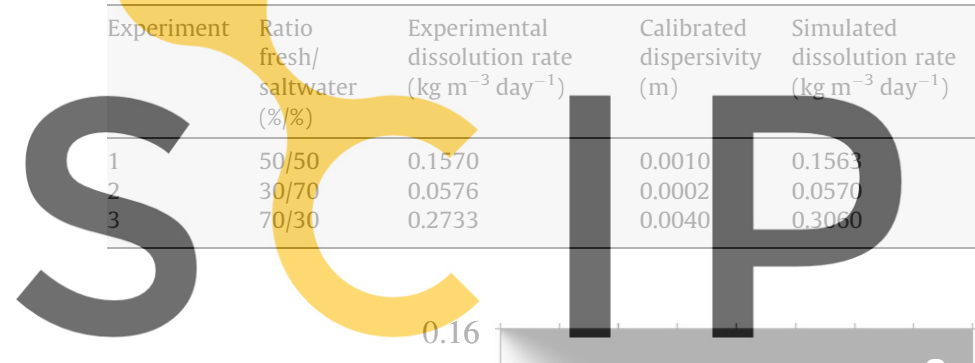

2

Register for free at https//www.scipedia.com to

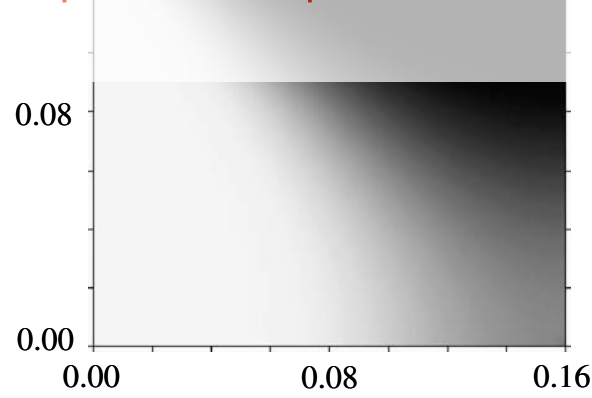

lated numerically through a simple discretization of the relationship between $c_{\mathrm{Ca}}$ and $\beta$

$\frac{\partial^{2} c_{\mathrm{Ca}}}{\partial \beta_{i}^{2}}=\frac{1}{\beta_{i+1}-\beta_{i-1}}\left(\frac{c_{\mathrm{Ca}, i+1}-c_{\mathrm{Ca}, i}}{\beta_{i+1}-\beta_{i}}-\frac{c_{\mathrm{Ca}, i}-c_{\mathrm{Ca}, i-1}}{\beta_{i}-\beta_{i-1}}\right)$,

where subscript $i$ refers to a mixing scenario. Alternatively, one could interpolate the $c_{\mathrm{Ca}}$ versus $\beta$ curve by means of a piece-wise continuous function and take the second derivative of the interpolating function.

\section{Modeling of the experiments}

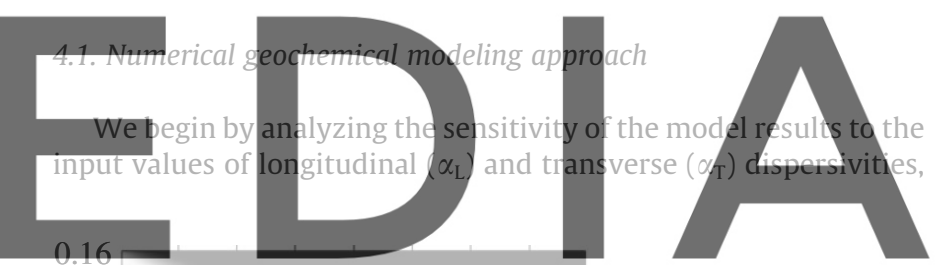

b

download the version without the watermark
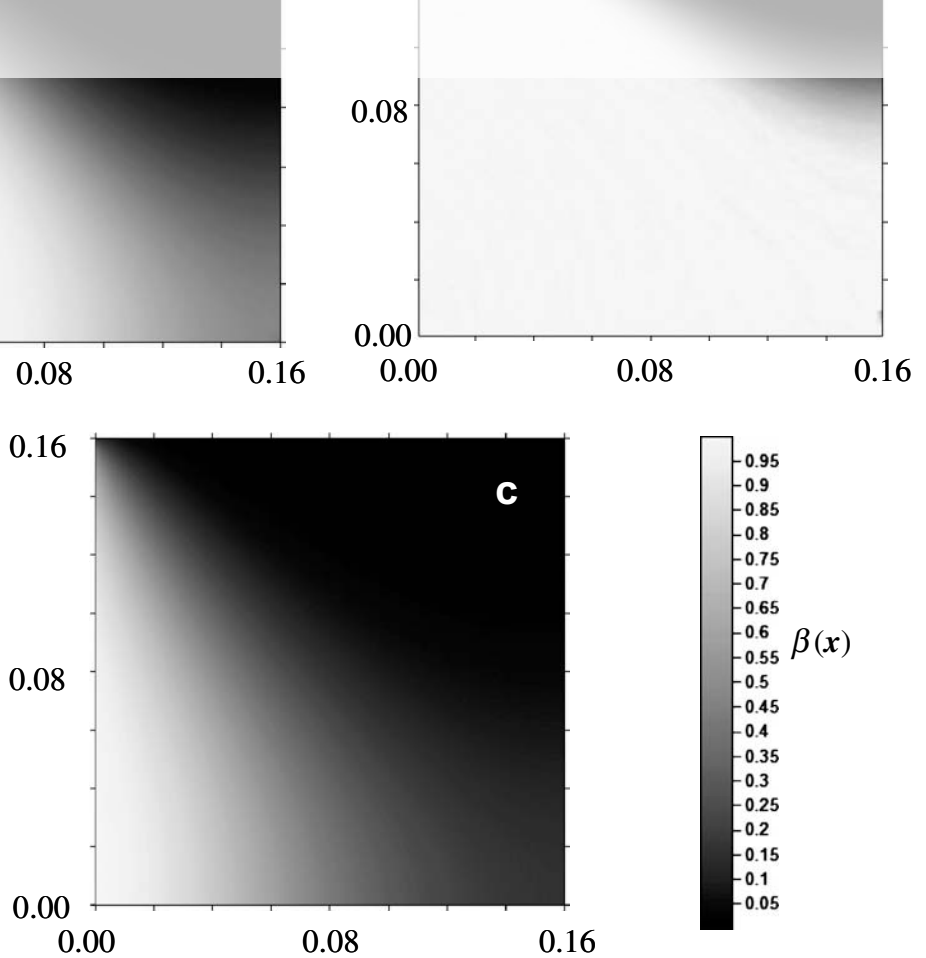

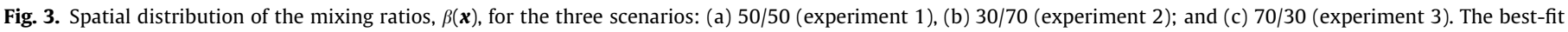
dispersivities reported in Table 6 were used in each case. 
using the fully numerical approach outlined in Section 3.2. Table 6 shows the calculated global dissolution rate in the system for experiment 1 of Table 1 (hereafter referred to as the "50/50 experiment") for different $\alpha_{\mathrm{L}}$ and $\alpha_{\mathrm{T}}$ values. The calculated rates should be compared against the value of 0.157 , as given in Table 2 . The results show that the pseudo-steady-state integrated dissolution rate within the system is more sensitive to transverse dispersivity than to longitudinal dispersivity; similar results were found for the other two experiments. On the other hand, our numerical simulations suggest that the impact of different values of longitudinal dispersivity can be seen during the initial phase of the experiment, i.e., when replacement of the water initially resident in the flow cell takes place. This observation must be taken into account so as to choose the appropriate flow design for evaluation of the complete dispersivity tensor in a given system. Due to lack of sensitivity of the model to $\alpha_{\mathrm{L}}$ and because the available data are associated only with pseudo-steady-state conditions, we choose to model the diffusion-dispersion process as isotropic, and set $\alpha_{L}=\alpha_{T}=\alpha$ as the only fitting parameter.

Fig. 2 illustrates the sensitivity of the temporal evolution of the cumulated difference between the outlet and the inlet $\mathrm{CaCO}_{3}$ concentrations on local (isotropic) dispersivity values as computed by RETRASO for the 50/50 experiment. Fig. 2a reports results of the calculations with reference to the beginning of the simulation. Fig. 2b shows cumulative concentration differences obtained after setting the time and concentration origin at the point at which the derivative of the curves in Fig. 2a first becomes positive [45],

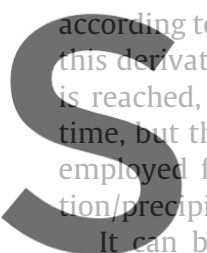
to the procedure adopted by vative becomes constant, a pset those of minerals (calcite) frequently to analyze the pitation in coastal aquifers be noted that the results of the nunerical model are strongly dependent on the selected value of dispersivity. This is elucidated clearly by the structure of the analytical expression (6). On

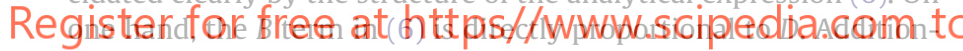
ally, $D$ also affects the spatial distribution (and thus the gradients) of the mixing ratio. As a consequence, the impact of $D$ on $r$ is highly nonlinear. Most notably, (i) the time at which the derivative of the cumulated difference between outlet and inlet concentrations of $\mathrm{CaCO}_{3}$ starts becoming positive increases with decreasing dispersivity, and (ii) increasing dispersivity from $0.001 \mathrm{~m}$ to $0.0025 \mathrm{~m}$ (and then from $0.0025 \mathrm{~m}$ to $0.009 \mathrm{~m}$ ) causes the estimated dissolution rate to increase by a factor of nearly 2 . In the absence of more precise documentation, and noting that the data reported in $[48,49]$ were collected after several pore volumes had been flushed from the system [45], calibration against measured values is performed after representing modeling results as in Fig. $2 \mathrm{~b}$.

For the same experiment, Singurindy et al. [49] used an isotropic dispersivity value of $\alpha=0.009 \mathrm{~m}$, representing a mixing distance of about 15 diameters of the calcium carbonate particles in the flow cell. Adopting Phillips' [33] formulation and some simplifying assumptions about the geometry of the reactive region, and evaluating the salinity gradient as the difference between the salinity of the fresh and saline waters divided by the maximum width of the mixing zone, Singurindy et al. [49] computed a global dissolution that was about 1.5 times larger than the experimental result. We note that the reported value of dissolution rate is less than half of that obtained with RETRASO upon setting $\alpha=0.009 \mathrm{~m}$. We therefore suggest that the simplified procedure adopted by Singurindy et al. [49] is inadequate to fully describe the global reaction rate of the system, and that detailed calibration of transport parameters through modeling is required.

Qualitative behaviors similar to those depicted in Fig. 2 were observed when modeling the remaining experiments. The calibra- tion procedure to match the experiments resulted in the following values of dispersivities: (a) $\alpha=0.0010 \mathrm{~m}$ for the $50 / 50$ experiment (experiment 1 in Table 1); and (b) $\alpha=0.0040 \mathrm{~m}$ for the $70 / 30$ experiment (experiment 3 in Table 1). Due to software constraints, it was not possible to adopt a grid refinement compatible with very low dispersivity values which would have been needed in order to obtain a good calibration of the 30/70 experiment (experiment 2 in Table 1); this point is discussed further in Section 4.2.

An interesting observation is that the isotropic dispersivity providing the best agreement against experimental results tends to decrease as the proportion of salt water increases. On the basis of our analysis, we believe this cannot be explained in terms of experimental uncertainties associated with measurements. Other factors which might contribute to this behavior include sensitivity of the modeled results to the chemical composition of the inlet waters, and temperature effects that could influence the activity coefficients. Also, from the modeling point of view, it is shown in the literature (e.g., $[3,20,29]$, and references therein) that a transport model based on a governing equation the format of which is that of the ADE often cannot adequately account for all of the relevant transport mechanisms under different flow regimes, even when solute displacement occurs within a seemingly homogeneous porous domain at the laboratory scale.

\subsection{Modeling approach based on the direct evaluation of reaction rates}

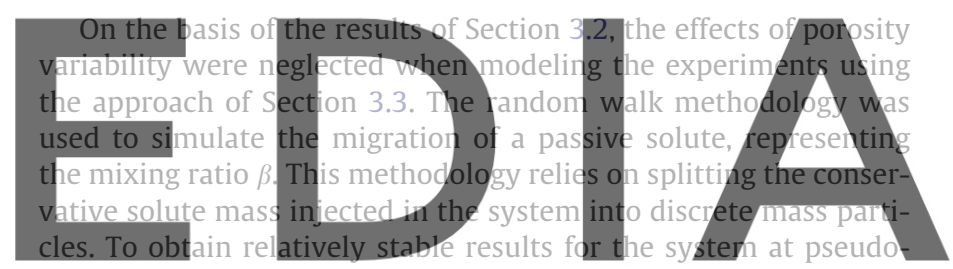

steady-state, 1.5 million particles were required in the simulation. The calibration procedure resulted in values of dispersivities

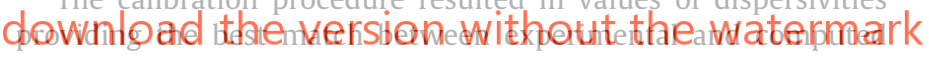
global reaction rates which coincide with those obtained by means of the fully numerical geochemical modeling approach for the $50 /$ 50 and 70/30 experiments. A good calibration of the 30/70 experiment against numerical modeling results obtained on the basis of (6) was obtained by adopting the isotropic dispersivity value $\alpha=0.0002 \mathrm{~m}$. Table 7 summarizes results of the numerical simulations for the three scenarios investigated, in terms of the dispersivities that provided the best matches between measured and modeled dissolution rates. Fig. 3 depicts the corresponding pseudo-steady-state spatial distribution of the mixing ratio, $\beta(\boldsymbol{x})$, calculated on the basis of the calibrated dispersivity values.

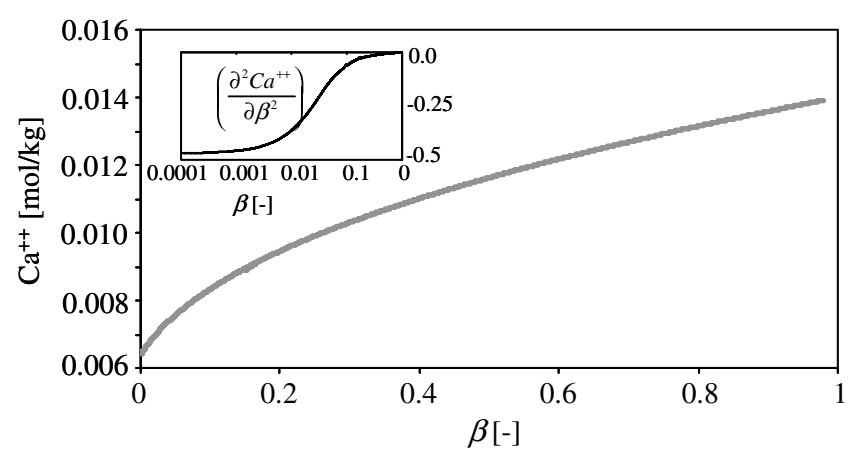

Fig. 4. Dependence of the calculated total aqueous $\mathrm{Ca}^{2+}$ concentration on $\beta$. The insert depicts the dependence of the chemistry-related term in (6), $A=\partial^{2} c_{\mathrm{Ca}} / \partial \beta^{2}$, on $\beta$. 
As indicated in Section 3.3, calculation of the nonlinear speciation term in (6) first requires evaluation of the dependence of the total aqueous $\mathrm{Ca}^{2+}$ concentration, $c_{\mathrm{Ca}}$, on $\beta$ (see Fig. 4). The dependence of $\partial^{2} c_{\mathrm{Ca}} / \partial \beta^{2}$ on $\beta$ was then obtained by first interpolating the plot by means of a polynomial function and then taking the second derivative of the interpolating function (Fig. 4, insert).

The spatial distribution of the pseudo-steady-state dissolution rates, $r(\boldsymbol{x})$, within the flow cell can then be computed on the basis of these results. Fig. 5a-c depicts the spatial distribution of $r(\boldsymbol{x})$ ( $\mathrm{mol} \mathrm{m}^{-3} \mathrm{~s}^{-1}$ ) calculated by (6) (dashed) for the three experiments on the basis of the dispersivities listed in Table 7. For comparison, Fig. 5a and $\mathrm{c}$ also shows the spatial distribution of $r(\boldsymbol{x})$ calculated by the fully numerical solution based on RETRASO (continuous curves). The inserts in the figures help to account for the individual contributions of the $A$ and $B$ terms in (6). While the latter is controlled by dispersion (related to Fig. 3 ), the former reflects the nonlinearity in the speciation and governs the sign of the reaction rate. The agreement between the two solutions is nearly perfect, thus strengthening our confidence in the use of the methodology proposed by De Simoni et al. $[12,13]$ to analyze these types of processes. Small discrepancies are due mainly to inaccuracies in the numerical evaluation of the second derivative of the speciation term.

It clearly emerges from Fig. 5 that dissolution tends to develop inside the freshwater part of the domain (low $\beta$ values, where freshwater is dominant) and is concentrated mostly near the inlet. This is in agreement with theoretical findings (e.g., [12,13]) and
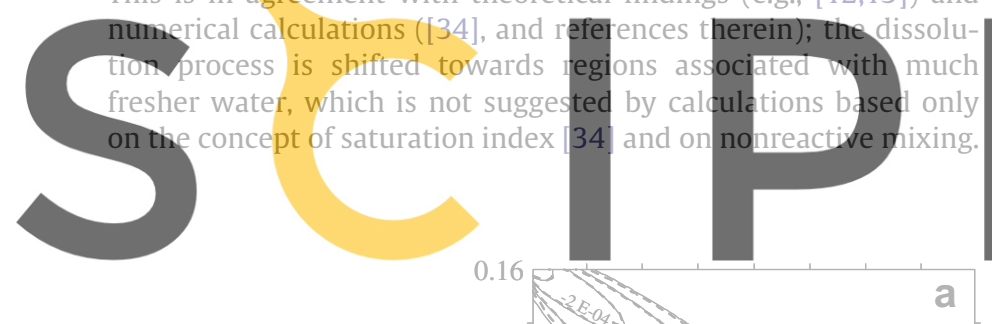

Register for free at https/_WWw.scipedia.com.to

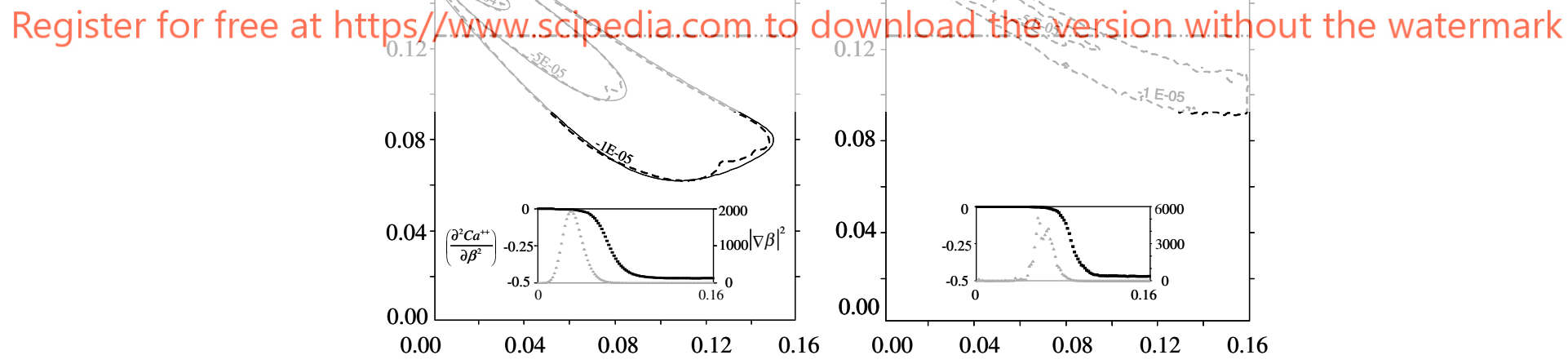

This in turn implies that the concept of saturation index is not a particularly relevant factor with respect to dissolution; rather it is the interaction between transport and chemical reactions that affects dissolution patterns.

While the detailed spatial distribution of $r(\boldsymbol{x})$ within the flow cell allows delineation of regions within which the geochemical process is most active, one is more interested, in many practical applications, in the global extent of the volume contributing to the observed process. In their experiments, Singurindy et al. $[48,49]$ estimated a mixing volume on the basis of global mass balance arguments, pointing out the difficulty associated with its direct measurement. The sizes of their estimated total mixing volume, relative to the volume of the flow cell, are $88.5 \%, 45 \%$, and $38.5 \%$, respectively, for experiments 1,2 , and 3 .

The actual demarcation of such a volume can be performed on the basis of modeling, by setting a lower cut-off value for the reaction rate below which the total dissolution rate is negligible. To help visualize this dependence, Fig. 6 shows the relative fraction of the total dissolved calcium carbonate versus the relative size of the mixing volume, $V_{\mathrm{r}} / V_{\text {cell }}\left(V_{\mathrm{r}}\right.$ being the reactive volume corresponding to a given lower cut-off for $r$ ). Calculation of $V_{\mathrm{r}}$ is performed by means of (6), upon varying the lower cut-off for $r(\boldsymbol{x})$ and for the dispersivity values listed in Table 7 . It can be noted that the relative proportion of the region within which about $50 \%$ of the dissolution occurs is not particularly sensitive to the proportions between saltwater and freshwater injected in the system. On the other hand, the experiment associated with the largest proportion

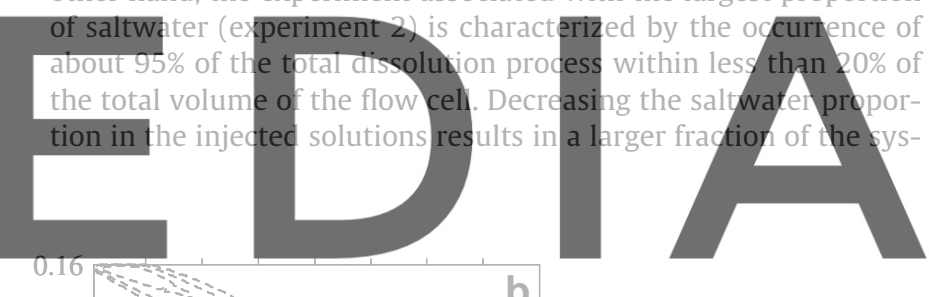

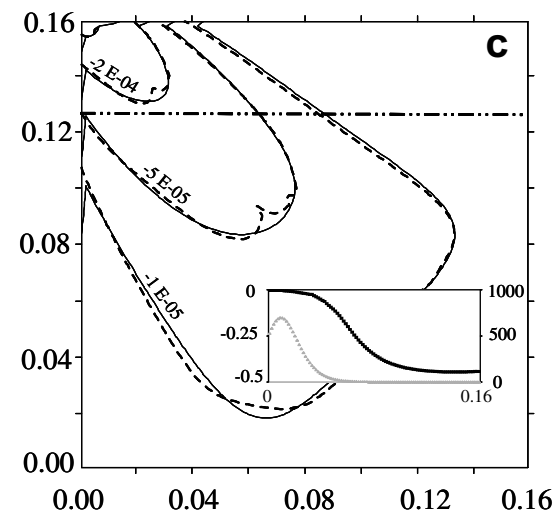

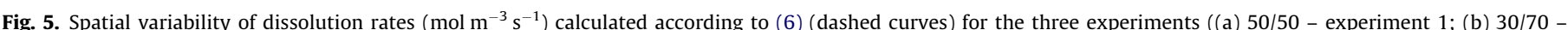

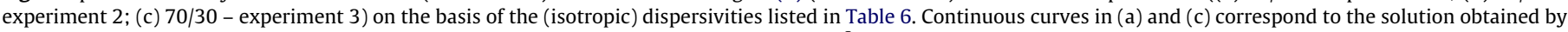

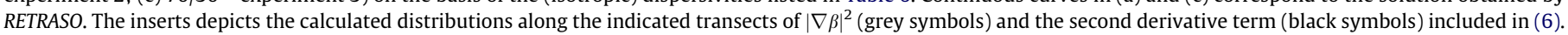




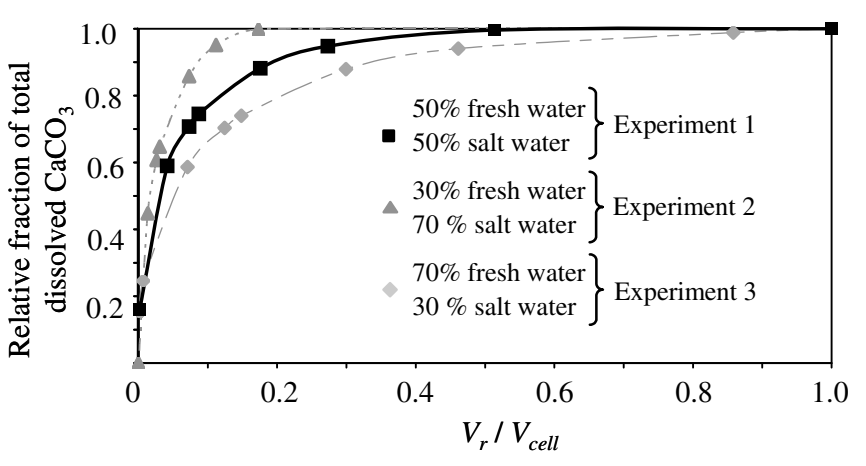

Fig. 6. Dependence of the numerically calculated relative fraction of the total dissolved calcium carbonate on the relative size of the mixing volume, $V_{\mathrm{r}} / V_{\text {cell }}$, obtained by means of the uncoupled analytical-numerical modeling approach for the (isotropic) dispersivity values listed in Table 6.

tem that contributes significantly to the dissolution process observed in the experiments.

\section{Discussion}

The salient points that can be extracted from our integrated use of the laboratory experiments reported in [48], a coupled flow and reactive transport numerical model, such as RETRASO, and the decoupled analytical-numerical methodology of De Simoni et al.

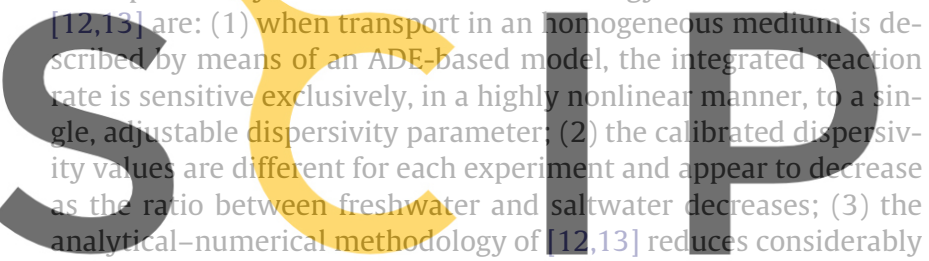
the complexity of the problem and overcomes potential limitations of Eulerian-based reactive transport codes, such as the need for re-

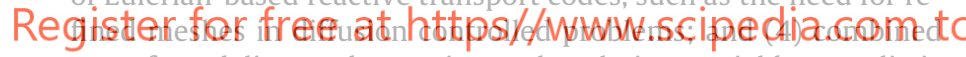
use of modeling and experimental techniques yields a realistic quantification of the key features of complex multicomponent, mixing-driven reactive problems.

The first finding is consistent with the work of Cirpka et al. [7] and indicates that it is possible to use flow cell reactive transport experiments to indirectly estimate dispersivities, by using a calibration process to fit observations taken at the inlet and outlet boundaries. In general, we expect the relative impact of longitudinal and transverse dispersivity upon the spatial distribution of reaction rates to be influenced by the type of flow and transport configuration. For instance, mixing in a two-dimensional homogeneous domain under uniform flow conditions is controlled by anisotropic dispersivities, and in several circumstances quantifying the transverse dispervisity is the key to proper description of the principal transport mechanism (e.g., [7,12,13], and references therein). This, in turn, is important in designing suitable laboratory experiments to evaluate relevant transport parameters.

In the modeled experiments, the calibrated (isotropic) dispersivity values are of the order of the pore size of the porous rock, thus being (in principle) suitable for describing mixing at the molecular scale. Although all calibrated values are within an order of magnitude, the variability in the values cannot be explained solely on the basis of error measurements and uncertainty. The fact that dispersivity is the main governing parameter in our formulation stems from our use of the ADE. This might also explain, at least in part, our inability to interpret all the experimental data by means of a unique dispersivity value. In the last few years, a body of literature has developed that questions the validity of models based on an ADE-type formulation (e.g., [3,20,29], and references therein), particularly for short travel (or residence) times and in the presence of boundaries. Modeling flow and transport of the experiments carried out here could incorporate a different choice of transport model (see [15] for the particular case of a multirate mass transfer transport equation). However, this will not affect the essence of the proposed analytical-numerical methodology; it will lead only to a different expression for (6), and to different calibration parameters from the experiments.

The modeling effort presented here demonstrates that the most significant part of the dissolution process is confined to a limited portion of the system. Knowledge of the spatial distribution of reaction rates is the relevant information needed to assess the actual shape of the region contributing to the reaction. As such, our results show that:

1. most of the reaction takes place within a very small part of the domain, characterized by a nonlinear combination of mixing and speciation (which in our case drives the dissolution front towards the freshwater inlet); and

2. mixing here is caused by diffusion, which theoretically affects (albeit slightly) the full domain; while a large fraction of the cell contributes to the total reaction, in some cases only a relatively small subdomain contributes to more than $90 \%$ of the global reaction rate.

The nearly perfect agreement between the results obtained on the basis of the fully numerical and uncoupled analytical-numerical geochemical nodeling methods, together with the excellent
comparison obtained against experimental data, denonstrates
the feasibility and advantage of using simple solutions to design
and then analyze laboratory experiments of quite complicated geo-
chemical problems. In particular, using the methodo/ogy proposed
by De Simoni et al. [12,13] to analyze these types of processes un-
der instantaneous equilibrium entails dedonstructug the problen according to the following steps:

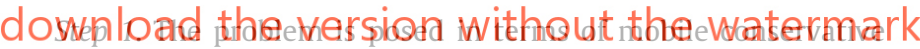 \\ components for the geochemical system analyzed, e.g., in terms of mixing ratios.}

Step 2. Transport is solved for each (conservative) mixing ratio, e.g., by means of any conventional transport or random walk particle tracking code.

Step 3. Speciation is performed to calculate the concentrations of the mobile species from those of the conservative components. This generally leads to nonlinear functional dependencies on mixing ratios and entails solving a nonlinear algebraic system of equations. Even though speciation might be computationally demanding, we note that it is a standard option on widely available speciation codes. Speciation calculations can then be performed for a pre-specified set of mixing ratios (e.g., considering two end-members, one could compute the solution for different $\beta$ values ranging between 0 and 1 ); then, in conjunction with solutions of steps (a) and (b), these calculations provide the spatial and temporal distribution of the concentration of the mobile species, thus leading to determination of the nonlinear speciation term in (6).

Step 4. Calculation of the spatial distribution of the reaction rates by (6).

The approach comprising these four steps presents some computational advantages with respect to the fully numerical one, as seen in the present application. An interesting feature is that it allows use of existing codes that treat only conservative transport to solve a reactive transport problem. This avoids, for example, the typical disadvantages of the discretization associated with Eulerian-based codes by resorting to Lagrangian-based codes. 


\section{Conclusions}

With few notable exceptions, most existing flow cell experiments do not allow direct mapping of the locations where reactions are effectively taking place. Rather, an integrated value is obtained by means of simple global mass balance calculations, and use of concentrations measured at the inlet and outlet boundaries of the cell. In some problems, though, integrated measurements of the reactive process are not sufficient, because local changes in the properties of the system are driven by point-wise distributions of reaction rates.

We provide a combination of numerical and analytical results to show how integrated measurements from a laboratory-scale experiment can be used jointly with (a) modern flow and reactive transport codes, or (b) the recent methodology of De Simoni et al. $[12,13]$ to gain insight about the actual spatial distribution of reaction rates within the porous system. The good agreement between the two modeling approaches, together with the excellent match obtained against experimental data, implies that it is possible to use simple solutions to design and then analyze laboratory experiments of quite complicated geochemical problems provided all reactions can be assumed in instantaneous geochemical equilibrium. In particular, the simple analytical-numerical methodology could be used directly and without the need for more time-consuming numerical runs to perform preliminary test designs. In terms of test design, we suggest that the concept of mixing volume must be defined carefully, because much of the reaction tends to

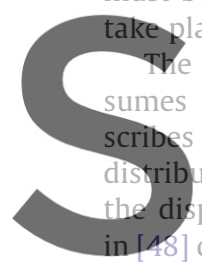
lace in only a small volume wit
specific application of the ap
thansport at the local scale.
ution of reaction rates is found to
could be used as a means to me
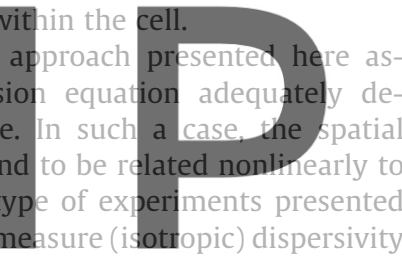
in a laboratory experiment. If a different model for transport of conservative solute is applied, the same general results remain va-

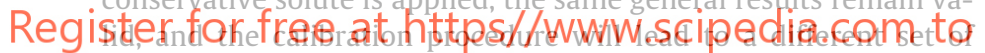
transport parameters.

\section{Acknowledgements}

Financial support by EU Project GABARDINE, and a research grant from the Jacob and Charlotte Lehrman Foundation, is gratefully acknowledged.

\section{References}

[1] Aucur AM, Tao FA, Moreira-Turcq P, Seyler P, Sheppard S, Benedetti MF. The Amazon River: behaviour of metals ( $\mathrm{Fe}, \mathrm{Al}, \mathrm{Mn}$ ) and dissolved organic matter in the initial mixing at the Rio Negro/Solimoes confluence. Chem Geol 2003; 197:271-85.

[2] Bear J. Dynamics of fluids in porous media. New York: American Elsevier; 1978.

[3] Berkowitz B, Cortis A, Dentz M, Scher H. Modeling non-Fickian transport in geological formations as a continuous time random walk. Rev Geophys 2006;44:RG2003. doi:10.1029/2005RG000178.

[4] Carrera J, Vázquez-Suñé E, Castillo O, Sanchez-Vila X. A methodology to compute mixing ratios with uncertain end-members. Water Resour Res 2004;40:W12101. doi:10.1029/2003WR002263.

[5] Chu M, Kitanidis PK, McCarty PL. Modeling microbial reaction at the plume fringe subject to transverse mixing in porous media: when can the rates of microbial reaction be assumed to be instantaneous? Water Resour Res 2005;41:W06002. doi:10.1029/2004WR003495.

[6] Cirpka OA, Frind EO, Helming R. Numerical simulation of biodegradation controlled by transverse mixing. J Contam Hydrol 1999;40:159-82.

[7] Cirpka OA, Olsson A, Ju Q, Rahman MDA, Grathwohl P. Determination of transverse dispersion coefficients from reactive plume lengths. Ground Water 2006;44(2):212-21.

[8] Cirpka OA, Valocchi AJ. Two-dimensional concentration distribution for mixing-controlled bioreactive transport in steady state. Adv Water Resour 2007;30(6-7):1668-79. doi:10.1016/j.advwatres.2006.05.022.
[9] Clement TP, Sun Y, Hooker BS, Petersen JN. Modeling multispecies reactive transport in ground water. Ground Water Monitor Remed 1998;18(2): 79-92.

[10] Corbella M, Ayora C, Cardellach E. Dissolution of deep carbonate rocks by fluid mixing: a discussion based on reactive transport modeling. J Geochem Explor 2003;78-9:211-4.

[11] Daccord G, Lietard O, Lenormand R. Chemical dissolution of a porous medium by a reactive fluid. 2. Convection vs. reaction behavior diagram. Chem Eng Sci 1993:48(1):179-86.

[12] De Simoni M, Carrera J, Sanchez-Vila X, Guadagnini A. A procedure for the solution of multicomponent reactive transport problems. Water Resour Res 2005;41:W11410. doi:10.1029/2005WR004056.

[13] De Simoni M, Sanchez-Vila X, Carrera J, Saaltink MW. A mixing ratios-based formulation for multicomponent reactive transport. Water Resour Res 2007;43:W07419. doi:10.1029/2006WR005256.

[14] Dijk P, Berkowitz B. Precipitation and dissolution of reactive solutes in fractures. Water Resour Res 1998;34(3):457-70.

[15] Donado LD, Sanchez-Vila X, Dentz M, Carrera J. Multi-component reactive transport in multi-continuum media; submitted for publication.

[16] Emmanuel S, Berkowitz B. Mixing-induced precipitation and porosity evolution in porous media. Adv Water Resour 2005;28:337-44.

[17] Fernàndez-Garcia D, Illangasekare TH, Rajaram H. Differences in the scale dependence of dispersivity and retardation factors estimated from forcedgradient and uniform flow tracer tests in three-dimensional physically and chemically heterogeneous porous media. Water Resour Res 2005;41(3), doi:10.1029/2004WR003523.

[18] Friedly JC, Rubin J. Solute transport with multiple equilibrium-controlled or kinetically controlled chemical reactions. Water Resour Res 1992;28(6):1935-53.

[19] Gramlin C, Harvey CF, Meigs L. Reactive transport in porous media: a comparison of model prediction with laboratory visualization. Environ Sci Technol 2002;36:2508-14

[20] Haggerty R, Gorelick SM. Multiple-rate mass transfer for modeling diffusion and surface reactions in media with pore-scale heterogeneity. Water Resour Res 2005;31(10):2383-400

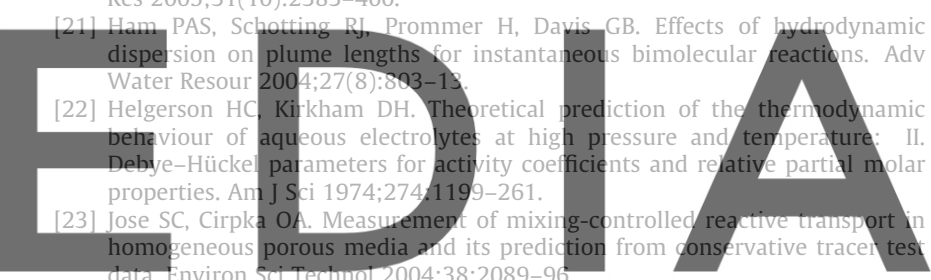

[24] Knutson CE, Werth CJ, Valocchi AJ. Pore-scale simulation of biomass growth

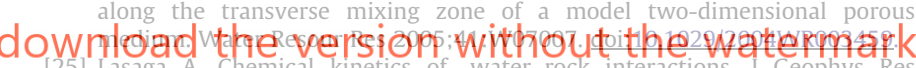
1984;89(B6):4009-25

[26] Lichtner. Continuous formulation of multicomponent-multiphase reactive transport. In: Lichtnei PC, Steefel CI, Oekiers EH, editors. Reactive transport in porous media. Reviews in mineralogy, vol. 34. Washington DC 1996; 83129.(DC): Miner. Soc. Amer.; 1996. p. 83-129.

[27] Liedl R, Valocchi AJ, Dietrich P, Grathwohl P. Finiteness of steady state plumes. Water Resour Res 2005;31(12):W12501. doi:10.1029/2005WR004000.

[28] Molins S, Carrera J, Ayora C, Saaltink MW. A formulation for decoupling components in reactive transport problems. Water Resour Res 2004;40(10):W10301. doi:10.1029/2003WR002970.

[29] Morales-Casique E, Neuman SP, Guadagnini A. Non local and localized analyses of nonreactive solute transport in bounded randomly heterogeneous porous media: theoretical framework. Adv Water Resour 2006;29(8):1238-55.

[30] Nambi I, Werth C, Sanford R, Valocchi AJ. Pore-scale analysis of anaerobic halorespiring bacterial growth along the transverse mixing zone of an etched silicon pore network. Environ Sci Technol 2003;37:5617-24.

[31] Palmer AN. Rates of limestone dissolution and calcite precipitation in cave streams of east-central New York State, northern section. Geol Soc Am 1996;28(3):89.

[32] Parkhurst DL, Appelo CAJ. User's guide to PHREEQC (Version 2) - a computer program for speciation, batch-reaction, one-dimensional transport, and inverse geochemical calculations. US Geological Survey Water-Resources Investigations Report 99-4259; 1999. 310p.

[33] Phillips OM. Flow and reactions in permeable rocks. New York: Cambridge University Press; 1991.

[34] Rezaei M, Sanz E, Raeisi E, Vázquez-Suñé E, Ayora C, Carrera J. Reactive transport modeling of calcite dissolution in the salt water mixing zone. J Hydrol 2005;311:282-98.

[35] Robinson BA, Viswanathan HS, Valocchi AJ. Efficient numerical techniques for modeling multicomponent ground-water transport based upon simultaneous solution of strongly coupled subsets of chemical components. Adv Water Resour 2000;23(4):307-24.

[36] Romanov D, Dreybrodt W. Evolution of porosity in the saltwater-freshwater mixing zone of coastal carbonate aquifers: an alternative modelling approach. J Hydrol 2006;329:661-73.

[37] Rubin J. Solute transport with multisegment, equilibrium-controlled reactions: a feed forward simulation method. Water Resour Res 1990;26(9):2029-55. 
[38] Rubin J. Solute transport with multisegment, equilibrium-controlled classical reactions: problem solvability and feed forward method's applicability for complex segments of at most binary participants. Water Resour Res 1992;28(6):1681-702.

[39] Rueedi J, Purtschert R, Beyerle U, Alberich C, Kipfer R. Estimating groundwater mixing ratios and their uncertainties using a statistical multiparameter approach. J Hydrol 2005;305:1-14.

[40] Saaltink MW, Ayora C, Carrera J. A mathematical formulation for reactive transport that eliminates mineral concentrations. Water Resour Res 1998;34(7):1649-56

[41] Saaltink MW, Carrera J, Ayora C. On the behavior of approaches to simulate reactive transport. J Contam Hydrol 2001;48:213-35.

[42] Saaltink MW, Batlle F, Ayora C, Carrera J, Olivella S. RETRASO, a code for modeling reactive transport in saturated and unsaturated porous media. Geol Acta 2004;2(3):235-51.

[43] Salamon P, Fernàndez-Garcia D, Gómez-Hernández JJ. A review and numerical assessment of the random walk particle tracking method. J Contam Hydrol 2006;87(3-4):277-305.

[44] Sanford WE, Konikow LF. Simulation of calcite dissolution and porosity changes in saltwater mixing zones in coastal aquifers. Water Resour Res 1989;25:655-67.

[45] Singurindy O. Personal communication; 2007.

[46] Singurindy O, Berkowitz B. Evolution of hydraulic conductivity by precipitation and dissolution in carbonate rock. Water Resour Res 2003;39(1):1016. doi:10.1029/2001WR001055
[47] Singurindy O, Berkowitz B. Dedolomitization and flow in fractures. Geophys Res Lett 2004;31:L24501. doi:10.1029/2004GL021594.

[48] Singurindy O, Berkowitz B, Lowell RP. Carbonate dissolution and precipitation in coastal environments: laboratory analysis and theoretical consideration. Water Resour Res 2004;40:W04401. doi:10.1029/2003WR002651.

[49] Singurindy O, Berkowitz B, Lowell RP. Correction to "Carbonate dissolution and precipitation in coastal environments: laboratory analysis and theoretical consideration". Water Resour Res 2005;41:W11701. doi:10.1029 2005WR004433.

[50] Steefel, MacQuarrie KTB. Approaches to modelling reactive transport. In: Reactive transport in porous media. Reviews in mineralogy, vol 34. Washington D.C.(DC): Miner. Soc. Amer.; 1996. p. 83-129.

[51] Tebes-Stevens C, Valocchi AJ, VanBriesen JM, Rittmann BE. Multicomponent transport with coupled geochemical and microbiological reactions: model description and example simulations. J Hydrol 1998;209(1-4):8-26.

[52] Tonkin JW, Balistrieri LS, Murray JW. Modeling metal removal onto natural particles formed during mixing of acid rock drainage with ambient surface water. Environ Sci Technol 2002;36:484-92.

[53] Yeh GT, Tripathi VS. A model for simulating transport of reactive multispecies components: model development and demonstration. Water Resour Res 1991;27(12):3075-94.

[54] Wen XH, Gómez-Hernández JJ. The constant displacement scheme for tracking particles in heterogeneous aquifers. Ground Water 1996;34(1):135-42.

[55] Witters HE. Chemical speciation dynamics and toxicity assessment in aquatic systems. Ecotoxicol Environ Saf 1998;41:90-5. 